\title{
CORRECTION
}

\section{Correction to: Big Data Analytics in Weather Forecasting: A Systematic Review}

\author{
Marzieh Fathi $^{1} \cdot$ Mostafa Haghi Kashani $^{2} \cdot$ Seyed Mahdi Jameii ${ }^{2}$ (D) Ebrahim Mahdipour ${ }^{1}$
}

Published online: 20 July 2021

(c) CIMNE, Barcelona, Spain 2021

\section{Correction to: \\ Archives of Computational Methods in Engineering https://doi.org/10.1007/s11831-021-09616-4}

This correction is published as vendor incorrectly labelled sub-section numbers related 5-7 and has been corrected as per original submission.

Original article has now been corrected.

Publisher's Note Springer Nature remains neutral with regard to jurisdictional claims in published maps and institutional affiliations.

The original article can be found online at https://doi.org/10.1007/ s11831-021-09616-4.

Seyed Mahdi Jameii jamei@qodsiau.ac.ir

Marzieh Fathi

marzieh.fathi@srbiau.ac.ir

Mostafa Haghi Kashani

mh.kashani@qodsiau.ac.ir

Ebrahim Mahdipour

mahdipour@srbiau.ac.ir

1 Department of Computer Engineering, Science and Research Branch, Islamic Azad University, Tehran, Iran

2 Department of Computer Engineering, Shahr-e-Qods Branch, Islamic Azad University, Tehran, Iran 